\title{
A Study on the Positional Relationships of Maxillary and Mandibular Central Incisors before and after Orthodontic Treatment
}

\author{
-With Reference to the Cases of Maxillary Protrusion-
}

\author{
By \\ Masanori OBARA
}

\section{Introduction}

Although there is available a fair amount of published literature on the positional relationships of maxillary and mandibular central incisors as well as of upper and lower lips, the present study is concerned with possible factors which would contribute toward the stability of maxillary and mandibular central incisors in the oral environment after orthodontic treatment and, further, with an elucidation of factors to evaluate an adequate positional relationship both after dynamic and static treatment periods.

\section{Material and Method}

\subsection{Materials}

Of the patients treated in the Department of Orthodontics, Nihon University School of Dentistry, a selective use was made of the cases who had been treated under more or less the same conditions. The basis of screening of the subjects was on the following criteria:

i. Those maxillary protrusion cases of Angle's Class 11 div. 1 and div. 2, having the overjet of more than $5 \mathrm{~mm}$.

ii. Those cases who had their first premolars extracted in conjunction with treatment by edgewise appliances.

iii. Those cases whose molar and canine relationships had been improved and whose retention was over 1 year.

iv. Those cases in whom proper positional relationshp of molars was judged as established at recall.

v. Those cases for whom no surgery was performed except for the purpose of convenient extraction, being free from dental defect, trismus, abnormalcy of temporomandibular joint, periodontal disease, etc.

\subsection{Method}

With a total of 25 subjects falling under any one of the above-mentioned conditions, their pre-, post-operative as well as recall cephalograms were examined in an effort to find out the positional relationships with respect to the maxillary 
Table 1 The study samples

\begin{tabular}{|c|c|c|c|c|c|c|}
\hline & Case & $\begin{array}{c}\text { Yrs. at which } \\
\text { treatment began }\end{array}$ & $\begin{array}{c}\text { Duration of } \\
\text { treatment }\end{array}$ & $\begin{array}{l}\text { Completion of } \\
\text { treatment }\end{array}$ & $\begin{array}{l}\text { Interval till } \\
\text { recall }\end{array}$ & Yrs. at recall \\
\hline $\begin{array}{l}q \\
0^{\prime}\end{array}$ & $\begin{array}{r}21 \\
4\end{array}$ & $\begin{array}{l}13 \text { ys. } 11 \mathrm{~ms} . \\
13 \text { ys. } 9 \mathrm{~ms} .\end{array}$ & $\begin{array}{l}4 \text { ys. } 5 \mathrm{~ms} . \\
4 \text { ys. } 5 \mathrm{~ms} .\end{array}$ & $\begin{array}{l}18 \text { ys. } 4 \mathrm{~ms} . \\
18 \text { ys. } 2 \text { ms. }\end{array}$ & $\begin{array}{l}3 \text { ys. } 4 \mathrm{~ms} . \\
2 \text { ys. } 11 \mathrm{~ms} .\end{array}$ & $\begin{array}{l}21 \text { ys. } 8 \mathrm{~ms} . \\
21 \text { ys. } 1 \mathrm{~ms} .\end{array}$ \\
\hline & $\begin{array}{l}01 \\
0^{1}\end{array}$ & 13 ys. $11 \mathrm{~ms}$. & 4 ys. $5 \mathrm{~ms}$. & 18 ys. $4 \mathrm{~ms}$. & 3 ys. $4 \mathrm{~ms}$. & 21 ys. $8 \mathrm{~ms}$ \\
\hline
\end{tabular}

1. SNtoFH

2. SNtoPalatal P.

3 . SNtoMand. P.

4. FHtoOccl. P.

5. FHtoMand. P.

6. SNA

7. FHtoNA

8. Convexity

9. SNB

10. $\mathrm{SN} \cdot \mathrm{Pog}$.

11. FHtoNB

12. Facial A.

13. $\mathrm{Y}$-axis

14. Gonial A.

15. ANB

16. Palatal to Mand.

17. ABtoSN

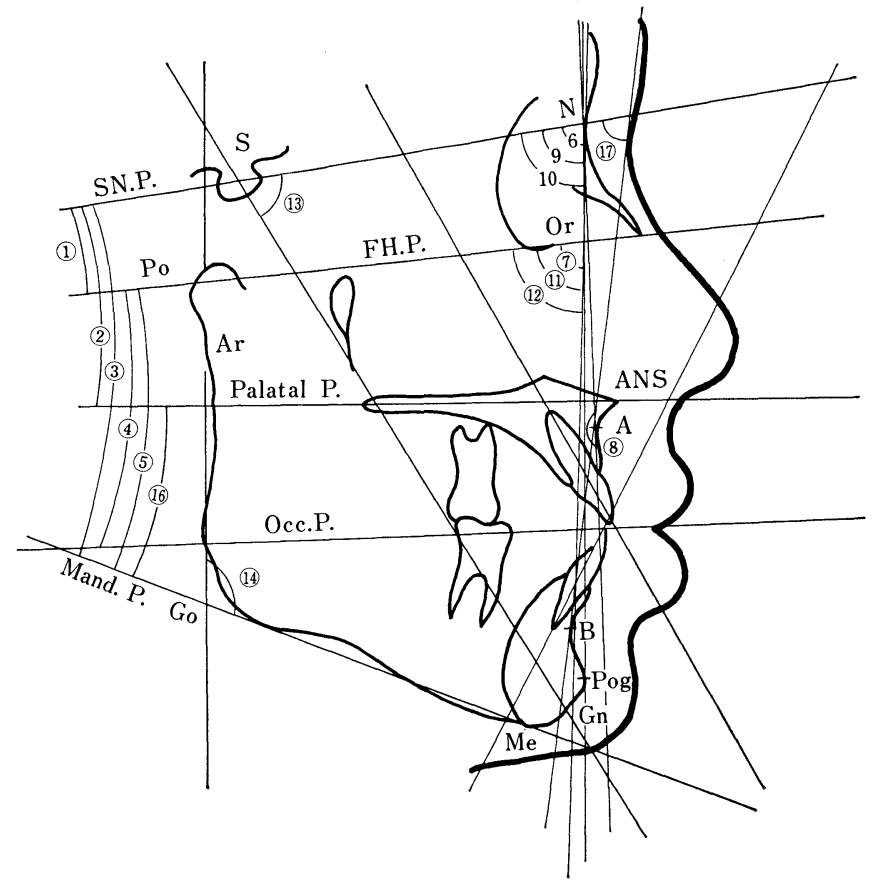

Fig. 1 A method for measuring angle landmarks

and mandibular central incisors, upper and lower lips and anterioposterior relationship of the maxilla and mandible. The study subjects are given in Table 1. The cephalographic analyses followed a method developed by IIzukA. As for the measurement of angle items, Downs, NoRTHWESTERN were adopted for the 17 parts (Figs. 1, 2).

\section{Findings}

The findings that came to light as a result of these efforts are given in Tables 2 to 5 .

\section{Discussion}

The angles and distances for the stability of maxillary and mandibular central 

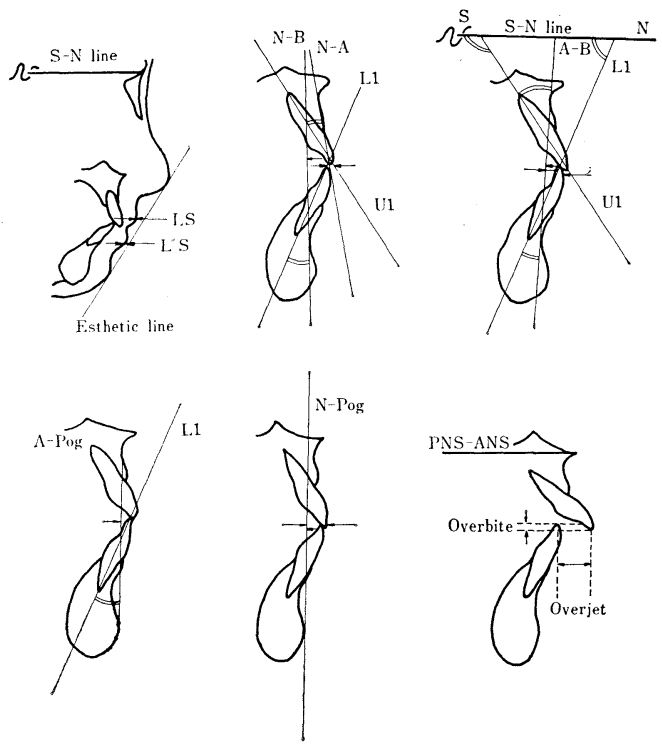

Fig. 2 A method for measuring maxillary and mandibular central incisors as well as upper and lower lips

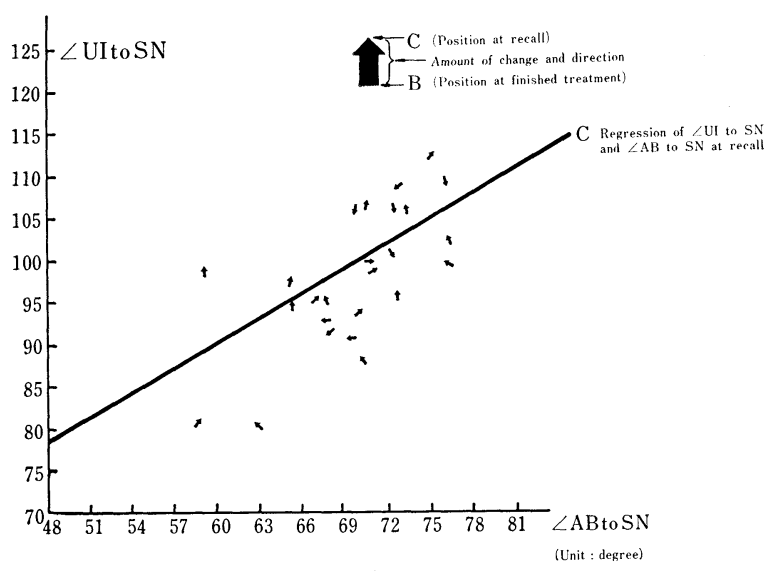

Fig. 3 Amounts of change and their directions during postoperative and recall periods

incisors revealed that $\angle \mathrm{L} 1$ to $\mathrm{AB}, \angle \mathrm{L} 1-\mathrm{AB}$ and $\angle \mathrm{L} 1$ to $\mathrm{A}$ pog. were relatively constant at the different stages of treatment.

Among the measurement items for maxillary and mandibular central incisors, maxilla and mandible as well as upper and lower lips, U1 to NA and L1 to NB were found to be lingually inclined in conjunction with an increase in $\angle$ ANB. 


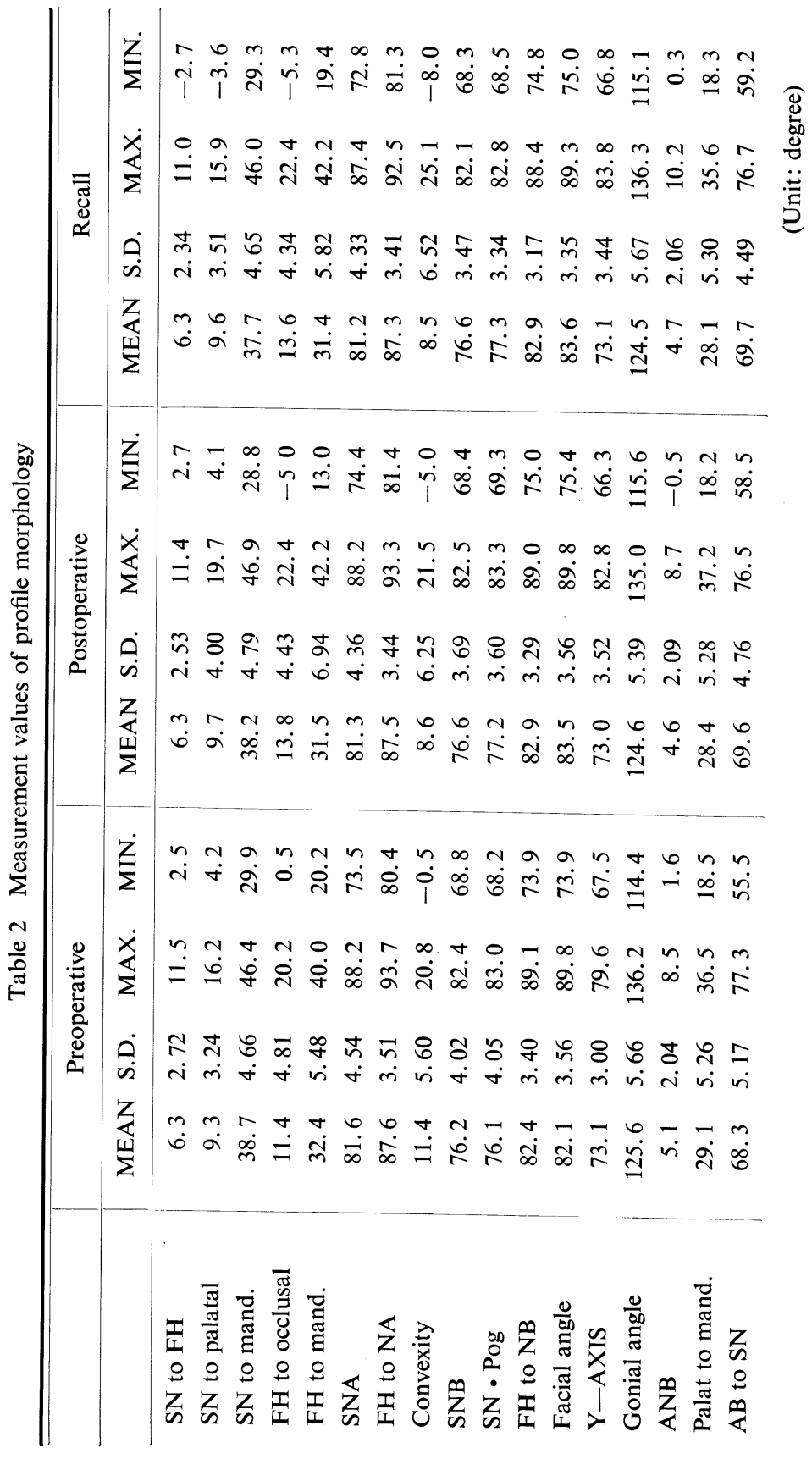




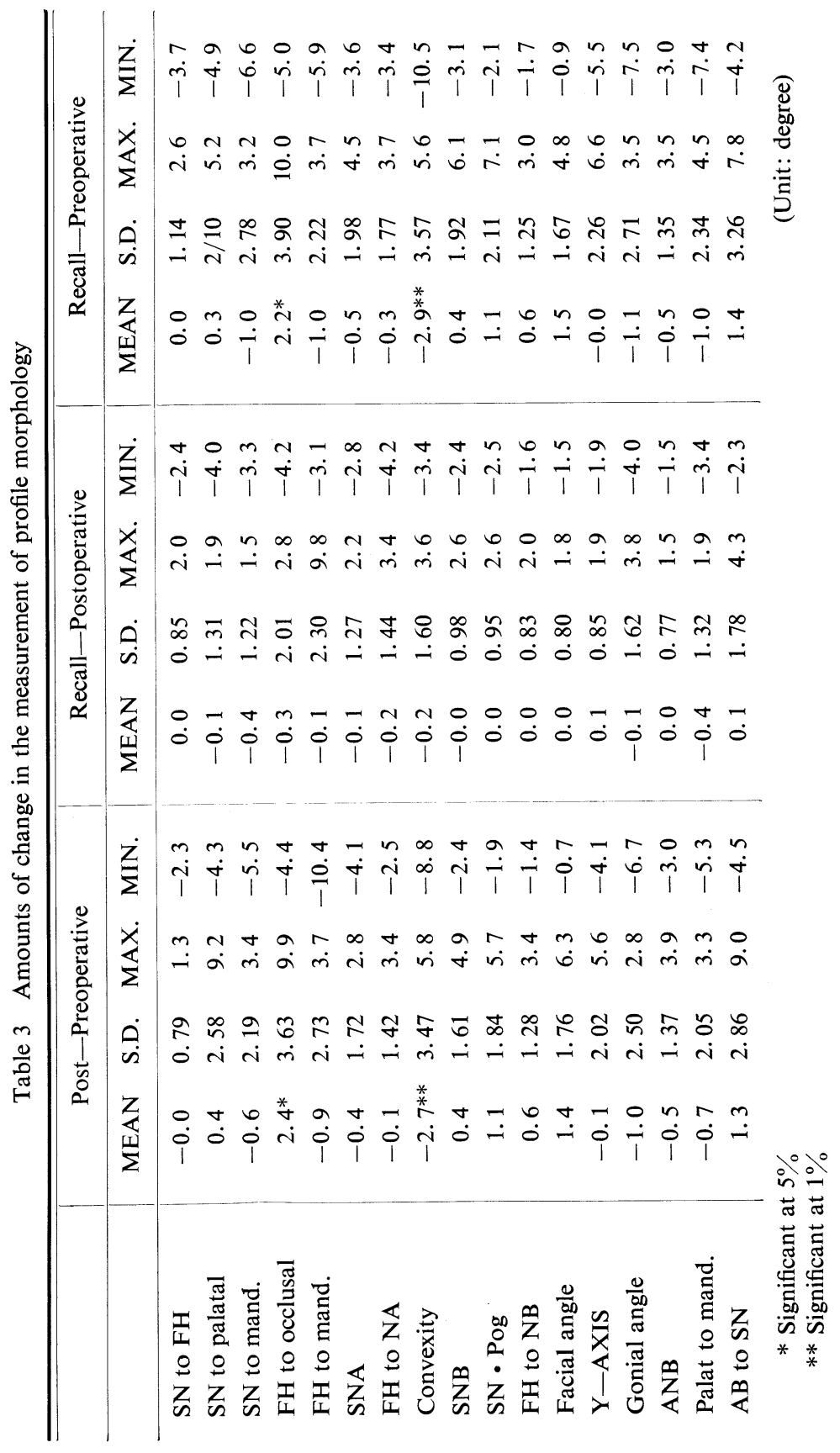




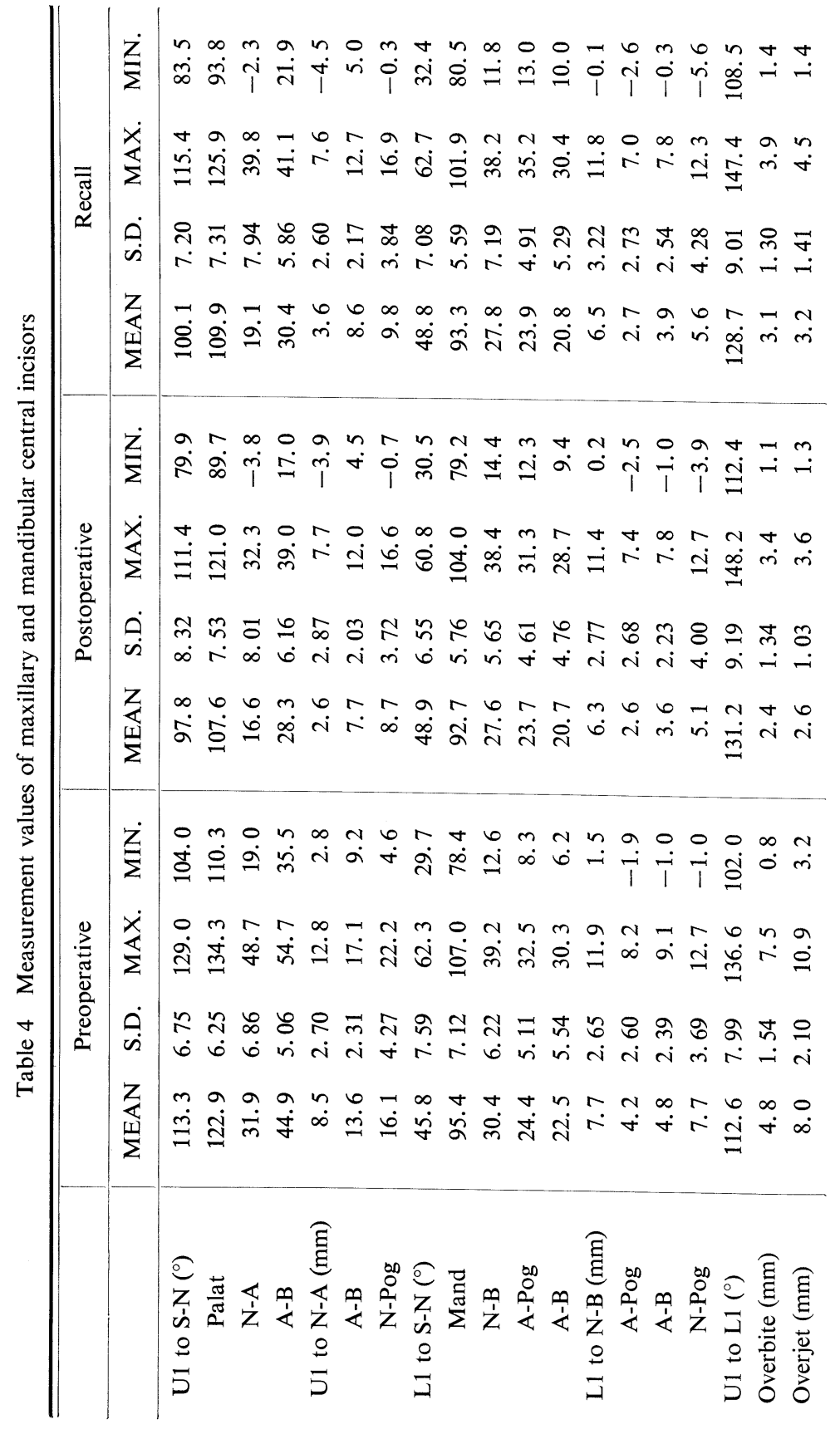




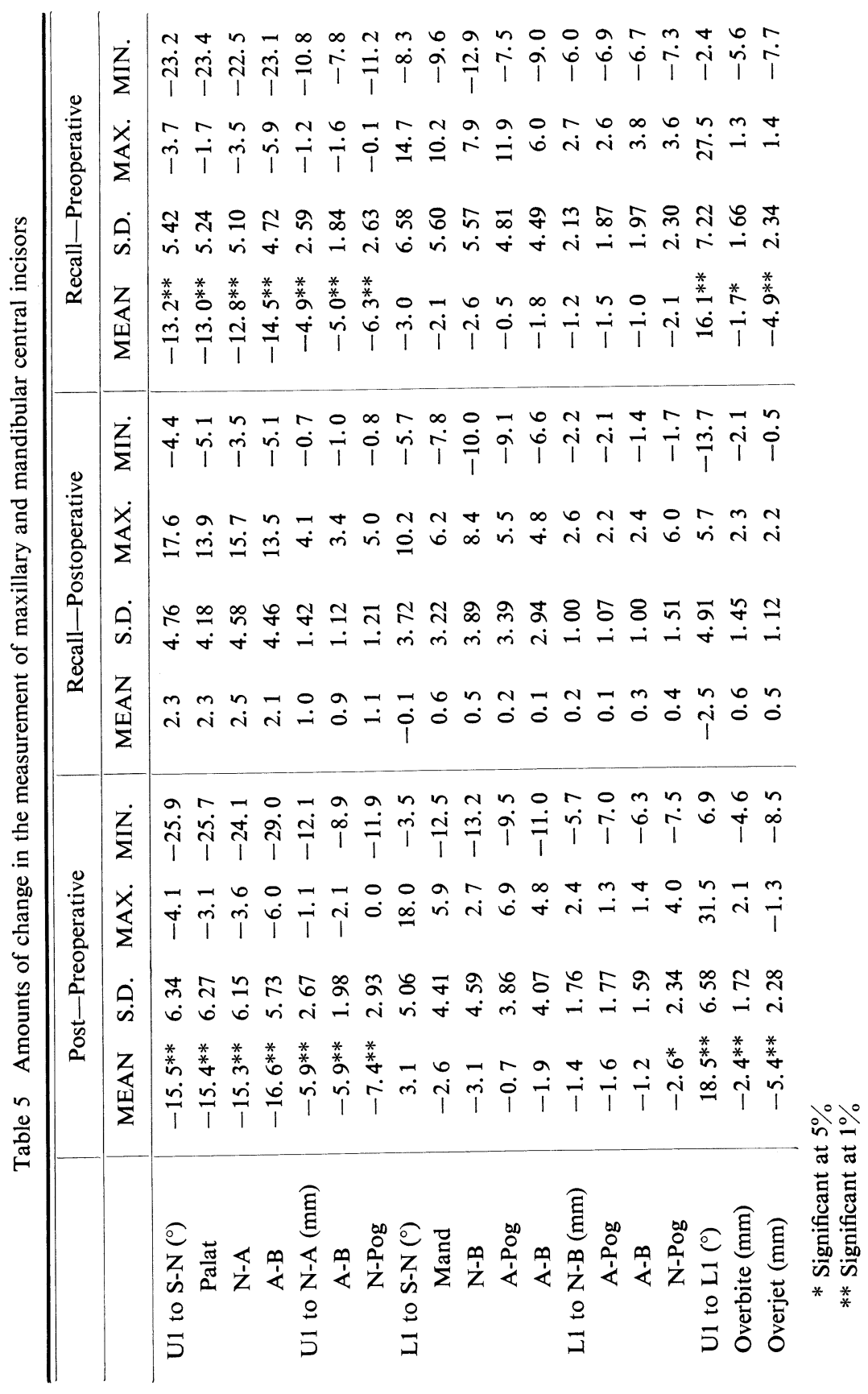


On the other hand, L1-NB showed a tendency in the direction of labial inclination. Postoperatively, these subjects showed different regression lines from those previously studied by SHISHIKURA concerning normal occlusal subjects.

The distance of U1-NA was found to have much progressed lingually as compared with normal subjects.

In particular, effect of esthetics was highly observed on the incisal edges, resembling more the facial features of the Europeans that are becoming to be favored by the Japanese. U1 to NA was preoperatively found to be more labially situated and this tendency was more or less observed postoperatively without a significant change.

This small difference may be attributed to the fact that the amount of posterior movement is relatively small but, at the same time, a change in NB line proportionately to the forward movement of mandible needs to be taken into consideration. In average values, there is no appreciable difference between preoperative and recall measurements but preoperative ANB crossed postoperative value at around $5^{\circ}$, the general trend being that the larger is ANB the more increased the axial inclination and the position of incisal edges are observed.

A regression line of $\mathrm{U} 1$ to $\mathrm{AB} \angle \mathrm{SN}$ is similar to that of $\mathrm{ANB}$ in pattern. These findings seem to be due to the facts that the diffusion of $\mathrm{AB} \angle \mathrm{SN}$ is larger than $\mathrm{ANB}$, correlative coefficient between $\angle \mathrm{ANB}$ and $\mathrm{AB} \angle \mathrm{SN}$ is nearly identical and SN serves as a relatively stable landmark, thus accounting for a small variation in the behavior of mandible during orthodontic treatment. ITO et al. previously reported that the degree of inclination and position of incisors are in a stable state to A-B line but, within the scope of the present study, regression lines of $U 1$ to $\mathrm{SN}$ and $\angle \mathrm{L} 1$ to $\mathrm{SN}$ preoperatively and at the time of recall are more or less distributed in parallel.

The position and inclination of the teeth artificially brought about by orthodontic treatment are naturally different from the normal ones. It is not that an average relapse will take place after removal of appliances but maxillary and mandibular central incisors show a tendency of relapse to $\angle \mathrm{AB}$ to $\mathrm{SN}$ as seen before orthodontic treatment.

Changes in the directions of maxillary and mandibular central incisors as well as the maxilla and mandible were examined by use of vectors (Table 5). Those cases that went into an opposite direction accounted for $24 \%$ and those which came to approximate the planned direction were $48 \% .56 \%$ showed an increase in U1 angle, $16 \%$ increased in $\mathrm{AB} \angle \mathrm{SN}$ and $32 \%$ showed a decrease. In terms of relapse, $\mathrm{AB}$ $\angle \mathrm{SN}$ decreased, whereas $\mathrm{U} 1 \angle \mathrm{SN}$ increased.

When correlations of maxillary and mandibular central incisors to E-LS and E-L"S were computed, the highest correlations were found in NP-U1 and L1, where NP-U1 revealed a decrease of $15 \mathrm{~mm}$ and the upper lip receded from E-line by $1.0 \mathrm{~mm}$. The amount of recession on the part of the lower lip was found to be less than that of the upper lip. Since part of the lower lip covers the maxillary anteriors, it is assumed that the lower lip will recede proportionaly to the recession of maxillary anteriors. 
At recall, difference of $0.1 \mathrm{~mm}$ for the upper lip and $-0.4 \mathrm{~mm}$ for the lower lip were measured as compared with normal values previously studied by SHISHIKURA.

\section{Conclusions}

As a result of the present study in which the positional relationships of maxillary and mandibular central incisors and those of maxillary and mandibular jaws before and after orthodontic treatment were examined, the author arrived at the following conclusions.

1. The position and axial inclination of maxillary and mandibular central incisors to NA and NB lines and the incisal edges of maxillary and mandibular central incisors were found to be statistically significant with respect to $\angle \mathrm{ANB}$ and $\angle \mathrm{AB}$ to $\mathrm{SN}$ items between the stages before and after orthodontic treatment, resulting in a straight regression.

2. The positional change of mandibular central incisal edges and axial inclination to $\mathrm{AB}$ line gave more or less the similar values.

After orthodontic treatment, the mean value $\angle 1$ to $\mathrm{AB}$ was $3.6 \mathrm{~mm} \angle 1$ to $\mathrm{AB}$ was $20.7^{\circ}$ and $\angle \mathrm{L} 1$ to $\mathrm{A}$ pogonion was $23.7^{\circ}$.

3. Straight regression of $\angle \mathrm{U} 1$ to $\mathrm{SN}$ and $\angle \mathrm{L} 1$ to $\mathrm{SN}$ in the direction of $\mathrm{AB}$ to $\mathrm{SN}$ revealed a tendency of their regressional coefficients being similar at recall.

From this finding, we can reasonably assume a relapse will not follow the average pattern.

4. There were found statistical differences between the positions of maxillary and mandibular central incisors to $\mathrm{N}$ pogonion line as well as between the positions of the upper and lower lips to E-line.

From these findings, we may conclude that $\mathrm{AB}$ line is an important landmark not only in the determination of maxillary and mandibular central incisors, but also serves as a useful tool for prognosis of orthodontic treatment.

There was observed a tendency that the positions of incisal edges to $A B$ line gave constant values in many cases, thus aiding in the compensation of an anterioposterior difference of maxilla and mandible by the inclination of dental axes.

The range of these compensatory angles before orthodontic treatment and at recall was found to be more or less of the same degree. 